\title{
Minimal persistent inflammation in Japanese cedar pollinosis and a prophylactic effect of intranasal corticosteroids
}

\author{
Yasuyuki Noyama ${ }^{1 *}$, Mitushiro Okano², Misato Hirai ${ }^{3}$, Takenori Haruna ${ }^{2}$, Kazunori Nishizaki ${ }^{2}$ \\ From 9th Symposium of Experimental Rhinology and Immunology of the Nose (SERIN 2013) \\ Leuven, Belgium. 21-23 March 2013
}

\section{Background}

Low doses of allergen exposure can cause an activation of inflammatory cells in nasal mucosa without an onset of nasal symptoms, called MPI (minimal persistent inflammation). MPI contributes to hyperreactivity and subsequently onset of the full-scale symptom. However, little is known whether MPI is present in JCP (Japanese cedar pollinosis). In addition, a prophylactic effect of intranasal corticosteroids on MPI in JCP has not been investigated.

\section{Method}

We designed a double-blinded, randomized, placebo-controlled, crossover trial. 20 patients with JCP and without perennial allergic rhinitis were enrolled. Nasal provocation test with low dose of allergen $(14.7 \mu \mathrm{g} /$ disc $)$ was performed once daily for 3 consecutive days. The levels of ECP and tryptase in nasal discharge were examined. Patients started to receive FFNS (fluticasone furoate nasal spray) or placebo one day before the first nasal provocation test.

\section{Result}

In placebo group, only $25 \%$ of patients showed positive response to the provocation test on day 1 . However, $75 \%$ and $68 \%$ of patients showed positive response on day 2 and day 3 , respectively. After the first provocation, the levels of ECP and tryptase were both significantly increased. These levels were not significantly different between the positive and negative responders, and the increase was seen even in the negative responders. Pretreatment with FFNS significantly suppressed the increase of nasal ECP and tryptase.

'Okayama University Graduate School of Medicine, Dentistry and

Pharmaceutical Sciences, Okayama, Japan

Full list of author information is available at the end of the article

\section{Conclusion}

These results suggest that MPI characterized by the upregulation of ECP and tryptase is present in JCP, and a prophylactic treatment with intranasal corticosteroids has a potential for controlling MPI in JCP.

\section{Author details \\ 'Okayama University Graduate School of Medicine, Dentistry and Pharmaceutical Sciences, Okayama, Japan. ${ }^{2}$ Okayama University Graduate School of Medicine, Dentistry and Pharmaceutical Sciences, Department of Otolaryngology-Head \& Neck Surgery, Okayama, Japan. ${ }^{3}$ Okayama Saiseikai General Hospital, Department of Otolaryngology-Head \& Neck Surgery, \\ Okayama, Japan}

Published: 16 July 2013

\section{doi:10.1186/2045-7022-3-S2-P27}

Cite this article as: Noyama et al:: Minimal persistent inflammation in Japanese cedar pollinosis and a prophylactic effect of intranasal corticosteroids. Clinical and Translational Allergy 2013 3(Suppl 2):P27.
Submit your next manuscript to BioMed Central and take full advantage of:

- Convenient online submission

- Thorough peer review

- No space constraints or color figure charges

- Immediate publication on acceptance

- Inclusion in PubMed, CAS, Scopus and Google Scholar

- Research which is freely available for redistribution

\section{() Biomed Central}

